\title{
Extracorporeal Membrane Oxygenation-Related Nosocomial Infection after Cardiac Surgery in Adult Patients
}

\author{
Jing Wang ${ }^{1}, \mathrm{MD}$; Liangshan Wang² ${ }^{2} \mathrm{PhD}$; Ming Jia², $\mathrm{PhD}$; Zhongtao $\mathrm{Du}^{2}$, PhD; Xiaotong $\mathrm{Hou}^{2}$, PhD
}

DOI: $10.21470 / 1678-9741-2020-0068$

\begin{abstract}
Introduction: The evaluation of extracorporeal membrane oxygenation-related nosocomial infection (ECMO-related $\mathrm{NI}$ ) in a homogeneous cohort remains scarce. This study analyzed ECMOrelated $\mathrm{NI}$ in adult patients who have undergone cardiac surgery.

Methods: From January 2012 to December 2017, 322 adult patients who have received ECMO support after cardiac surgery were divided into the infection group $(n=131)$ and the noninfection group $(n=191)$. ECMO-related NI was evaluated according to demographic data, surgical procedures, and ECMO parameters.

Results: The incidence of ECMO-related NI was 85.4 cases per 1000 ECMO days. Acinetobacter baumannii was the most common pathogen causing blood stream infection and respiratory tract infection. Prolonged duration of surgery $(P=0.042)$ and cardiopulmonary bypass assist $(P=0.044)$ increased the risk of
\end{abstract}

ECMO-related NI. Body mass index (odds ratio [OR]: 1.077; $95 \%$ confidence interval $[\mathrm{Cl}]$ : $1.004-1.156 ; P=0.039)$ and duration of ECMO support (OR: $1.006 ; 95 \% \mathrm{Cl}$ : 1.003-1.009; $P=0.0001$ ) were the independent risk factors for ECMO-related NI. Duration of ECMO support > 144 hours (OR: 2.460; 95\% Cl: 1.155-7.238; $P<0.0001$ ) and ECMO-related NI (OR: 3.726; 95\% Cl: 1.274-10.895; $P=0.016$ ) increased significantly the risk of in-hospital death.

Conclusion: Prolonged duration of ECMO support was an independent risk factor for NI. Surgical correcting latent causes of cardiopulmonary failure and shortening duration of ECMO whenever possible would reduce susceptibility to NI.

Keywords: Cross Infection. Extracorporeal Membrane Oxygenation. Odds Ratio. Incidence. Risk Factors. Body Mass Index. Hospital Mortality. Cardiac Surgical Procedures.

\begin{tabular}{lllll}
\hline \multicolumn{2}{l}{ Abbreviations, acronyms \& symbols } & & \\
\hline $\mathrm{BMI}$ & $=$ Body mass index & ICU & $=$ Intensive care unit \\
$\mathrm{BSI}$ & $=$ Blood stream infection & LVEF & $=$ Left ventricular ejection fraction \\
$\mathrm{CABG}$ & $=$ Coronary artery bypass grafting & NI & $=$ Nosocomial infection \\
$\mathrm{CI}$ & $=$ Confidence interval & NYHA & $=$ New York Heart Association \\
$\mathrm{CPB}$ & $=$ Cardiopulmonary bypass & OR & $=$ Odds ratio \\
CRRT & $=$ Continuous renal replacement therapy & RTI & $=$ Respiratory tract infection \\
ECMO & $=$ Extracorporeal membrane oxygenation & SWI & $=$ Sternal wound infection \\
ECMO-related NI & $=$ Extracorporeal membrane oxygenation-related & UTI & $=$ Urinary tract infection \\
& nosocomial infection & VA & $=$ Venoarterial \\
ELSO & $=$ Extracorporeal Life Support Organization & & \\
\hline
\end{tabular}

'Management Office of Nosocomial Infection, Beijing Anzhen Hospital, Capital Medical University, Beijing, People's Republic of China.

${ }^{2}$ Center for Cardiac Intensive Care, Beijing Anzhen Hospital, Capital Medical University, Beijing, People's Republic of China.

This study was carried out at the Beijing Anzhen Hospital, Capital Medical University, Beijing, People's Republic of China.
Correspondence Address:

Xiaotong Hou

(iD) https://orcid.org/0000-0001-9536-7400

Center for Cardiac Intensive Care, Beijing Anzhen Hospital, Capital Medical University Anzhen Street No.2 Chaoyang District, 100029, Beijing, People's Republic of China Zip Code: 100029

E-mail:xt.hou@ccmu.edu.cn. 


\section{INTRODUCTION}

Extracorporeal membrane oxygenation (ECMO) is one of the most important life support techniques for patients with severe but reversible cardiac and/or pulmonary failure. Despite advance in technique and management of ECMO, nosocomial infection $(\mathrm{NI})$ is still one of severe complications of ECMO that remarkably increases morbidity and mortality ${ }^{[1]}$.

Comparing with other patients in intensive care unit (ICU), the patients undergoing ECMO are with increasing possibility of $\mathrm{NI}$ due to cannulation disrupting the skin barrier and allowing pathogens invasion and the hollow fiber structure of the oxygenator contributing to pathogens establishment ${ }^{[2,3]}$. Several studies have analyzed the risk factors and pathogens of ECMOrelated $\mathrm{NI}^{[4-6]}$, but different studies have obvious heterogeneity from baseline characteristics including populations (pediatric vs. adult patients), number of patients, concomitant diseases, causes of cardiac or pulmonary failure, ECMO cannulation access (percutaneous vs. intrathoracic), and ECMO support mode (venoarterial [VA] vs. venovenous). Such heterogeneity may affect the incidence, risk factors, and pathogens of ECMO-related NI.

In addition, the data on ECMO-related $\mathrm{NI}$ in adult patients after cardiac surgery remain scarce.

Therefore, we focused on ECMO and cardiac surgery parameters and investigated a single-center large sample homogenous group to analyze the incidence, risk factors, and pathogens of ECMO-related $\mathrm{NI}$ in adult patients who have undergone cardiac surgery and VA-ECMO support.

\section{METHODS}

\section{Patient Population}

From January 2012 to December 2017, a total of 35,327 adult patients underwent cardiac surgery at the Beijing Anzhen Hospital, Capital Medical University, People's Republic of China. Among those patients, 463 suffering from severe but reversible cardiac and/or pulmonary failure received ECMO support. This study's inclusion criteria were: (1) age $\geq 18$ years; (2) intraoperative or postoperative ECMO support; (3) no infection identified by specimen culture (blood, sputum, urine, or wound secretion, etc.) before ECMO support; (4) VA-ECMO support $\geq 48$ hours.

According to the inclusion criteria, 322 patients were recruited to this study. Baseline characteristics, surgical parameters, ECMO parameters, and in-hospital outcomes were reviewed from medical records. This is a retrospective cohort study in accordance with the Ethical Guideline of the Committee on Human Experimentation of our institution, and the informed consent was obtained from the patients.

\section{ECMO Procedures}

The indications for ECMO were identified by extracorporeal life support physicians and cardiac surgeons. VA-ECMO mode with cannulation via femoral artery and vein was a predominant procedure duo in all patients who underwent cardiac surgery. Systemic anticoagulation was achieved by continuous intravenous heparin infusion to maintain activated clotting time in a range of 180-200 s. ECMO flow was initially set with a rate of $100 \mathrm{ml} / \mathrm{kg} / \mathrm{min}$ and the flow level was tailored to achieve adequate tissue perfusion evaluated by lactate level and endorgan function. The management protocols of ECMO followed the Extracorporeal Life Support Organization (ELSO) guidelines ${ }^{[7]}$.

\section{Respiratory Management During ECMO}

Lung-protective ventilatory strategies were employed during ECMO support. The parameters of mechanical ventilation included: tidal volume 4-6 ml/kg (ideal body weight), respiratory rate $<12 / \mathrm{min}$, inhaled oxygen concentration 30-40\%, positive end-expiratory pressure 6-10 $\mathrm{cmH}_{2} \mathrm{O}$, and airway platform pressure $<25 \mathrm{cmH}_{2} \mathrm{O}$. The protocols of extubation included: (1) sober mind, good limb movement, strong airway self-cleaning ability; (2) hemodynamic stability, normal central venous pressure; (3) adequate tissue perfusion, serum lactate concentration < $3 \mathrm{mmol} / \mathrm{L}$, urine $>1 \mathrm{ml} /\left(\mathrm{kg}^{*} \mathrm{~h}\right)$ under sufficient blood volume or continuous renal replacement therapy; (4) $\mathrm{PaO}_{2} / \mathrm{FiO}_{2}>200$ $\mathrm{mmHg}$ without pulmonary edema; (5) no predictable secondary thoracotomy.

\section{Definition of ECMO-Related NI}

$\mathrm{NI}$ occurring $24 \mathrm{~h}$ after initiation and $48 \mathrm{~h}$ after discontinuation of ECMO was defined as ECMO-related $\mathrm{N}^{[8]}$. The type of ECMOrelated $\mathrm{NI}$ included blood stream infection $(\mathrm{BSI})$, respiratory tract infection (RTI), urinary tract infection (UTI), and sternal wound infection (SWI). The diagnosis and definition of ECMO-related NI were based on the Centers for Disease Control and Prevention definitions for $\mathrm{NI}^{\left[{ }^{9]}\right.}$. Isolation of pathogenic microorganisms was related to clinical symptoms, typical inflammation characteristics in blood samples, and radiographic findings.

\section{Anti-Infective Therapy}

Patients received antibiotic prophylaxis with secondgeneration cephalosporins at initiation of ECMO support. If ECMO-related NI occurred, antibiotic was adjusted according to the culture results. The conventional dose of antibiotic was started and regulated according to renal function and drug concentration monitoring.

\section{Statistical Analysis}

Statistical analysis was performed using an extensively admissive software program, the SAS software (SAS Institute Inc 2013. SAS/ACCESS ${ }^{\circledR} 9.4$ Interface to ADABAS: Reference. Cary, NC: SAS Institute Inc.). Continuous data and categorical data were expressed as mean \pm standard deviation and percentage, respectively. Variance test was used to address nonpaired samples for comparing normally distributed parameters, and Wilcoxon rank sum test was used for comparing nonparametric variables. The qualitative variables were compared using chisquared test or Fisher's exact probability test. The multiple logistic regression analysis was conducted to identify the risk factors of ECMO-related NI, BSI, and in-hospital death. $\mathrm{P}<0.05$ was considered to be statistically significant. 


\section{RESULTS}

\section{Baseline Characteristics and In-Hospital Outcomes of ECMO Support}

The total ECMO support time in 322 patients was 1675.34 days. The average age of this cohort was $57.19 \pm 11.85$ years, and male patients accounted for $74.22 \%(n=239)$. Patients in the infection group underwent longer duration surgeries $(447.92 \pm 206.07 \mathrm{~min}$ vs. 402.35 $\pm 191.35 \mathrm{~min}, P=0.042$ ) and received higher percentage of cardiopulmonary bypass (CPB) assist (58.02\% vs. $46.60 \%$, $P=0.044$ ) than those in the non-infection group. Detailed baseline characteristics were showed in Table 1.

Comparing with the non-infection group, the patients in the infection group underwent longer ECMO support (153.53 \pm 105.33 hours vs. 105.21 \pm 71.79 hours, $P<0.001)$ with lower ECMO weaning rate (56.49\% vs. $70.16 \%, P=0.012)$; details were presented in Table 2. Regarding major complications and outcomes, acute renal failure requiring continuous renal replacement therapy $(42.75 \%$ vs. $31.41 \%, P=0.037$ ) was more common and survival rate to discharge was lower $(41.98 \%$ vs. $53.92 \%, P<0.001)$ in the infection group than in the non-infection group (Table 3).

\section{Incidence and Pathogenic Microorganisms of NI}

Among 322 patients, 131 suffered from a total of 143 infectious events. These included 40 cases of BSI, 76 cases of RTI, 10 cases of UTI, and 17 cases of SWI. The incidence of ECMO-related NI was 85.4 cases per 1000 ECMO days. The incidences of ECMO-related $\mathrm{NI}$ and $\mathrm{BSI}$ were gradually increased with prolonging duration of ECMO support (Figure 1). The receiver operating characteristic curve showed that a cutoff value was 92 hours (sensitivity 0.794, specificity 0.497), which indicated a significantly increased risk of $\mathrm{NI}$ with ECMO support > 92 hours (Figure 2).

Gram-negative bacteria were predominant pathogens and accounted for $64.01 \%$ of the total culture-positive pathogens, Gram-positive bacteria for $27.75 \%$, and fungi for $8.24 \%$. Acinetobacter baumannii was the most common pathogen of

Table 1. Baseline characteristics of ECMO populations.

\begin{tabular}{|c|c|c|c|c|}
\hline Variables & All patients $(n=322)$ & $\begin{array}{l}\text { Infection group } \\
\qquad(n=131)\end{array}$ & $\begin{array}{l}\text { Non-infection group } \\
\qquad(n=191)\end{array}$ & $P$-value \\
\hline Age (year) & $57.19 \pm 11.85$ & $57.02 \pm 12.35$ & $57.30 \pm 11.52$ & 0.959 \\
\hline Male (\%) & $239(74.22)$ & $98(74.81)$ & $141(73.82)$ & 0.897 \\
\hline $\mathrm{BMI}$ & $24.35 \pm 3.57$ & $24.81 \pm 3.55$ & $24.04 \pm 3.55$ & 0.126 \\
\hline Hypertension & $156(48.45)$ & $66(50.38)$ & $90(47.12)$ & 0.573 \\
\hline Diabetes mellitus & $72(22.36)$ & $32(24.43)$ & $40(20.94)$ & 0.497 \\
\hline Chronic pulmonary disease & $8(2.48)$ & $2(1.53)$ & $6(3.14)$ & 0.480 \\
\hline \multicolumn{5}{|l|}{ NYHA class } \\
\hline | or || & $206(63.98)$ & $79(60.30)$ & $127(66.49)$ & 0.256 \\
\hline III or IV & $116(36.02)$ & $52(39.70)$ & $64(33.51)$ & \\
\hline LVEF & $49.35 \pm 8.41$ & $48.76 \pm 9.06$ & $49.75 \pm 8.26$ & 0.311 \\
\hline \multicolumn{5}{|l|}{ Timing of operation } \\
\hline Scheduled operation & $285(88.51)$ & $117(89.31)$ & 168 (87.96) & 0.859 \\
\hline Emergency operation & $37(11.49)$ & $14(10.69)$ & $23(12.04)$ & \\
\hline \multicolumn{5}{|l|}{ Type of operation } \\
\hline CABG & $254(78.88)$ & $97(74.05)$ & $157(82.20)$ & 0.078 \\
\hline Cardiac valves surgery & $58(18.01)$ & $28(21.37)$ & $30(15.71)$ & \\
\hline Other cardiac surgeries & $10(3.11)$ & $6(4.58)$ & $4(2.09)$ & \\
\hline Reoperation & $22(6.83)$ & $11(8.40)$ & $11(5.76)$ & 0.376 \\
\hline Duration of operation (min) & $420.78 \pm 200.20$ & $447.92 \pm 206.07$ & $402.35 \pm 191.35$ & 0.042 \\
\hline Use of CPB & $165(51.24 \%)$ & $76(58.02 \%)$ & $89(46.60 \%)$ & 0.044 \\
\hline
\end{tabular}

$\mathrm{BMI}=$ body mass index; $\mathrm{CABG}=$ coronary artery bypass grafting; $\mathrm{CPB}=$ cardiopulmonary bypass; $\mathrm{ECMO}=$ extracorporeal membrane oxygenation; LVEF=left ventricular ejection fraction; NYHA=New York Heart Association 
Table 2. Patients'ECMO-related parameters and outcomes.

\begin{tabular}{|c|c|c|c|}
\hline Variables & $\begin{array}{l}\text { Infection group } \\
(n=131)\end{array}$ & $\begin{array}{l}\text { Non-infection group } \\
(n=191)\end{array}$ & $P$-value \\
\hline \multicolumn{4}{|l|}{ Indications for ECMO support } \\
\hline Failure to wean off CPB & $21(16.03)$ & $36(18.85)$ & 0.541 \\
\hline Refractory cardiac-pulmonary failure & $98(74.81)$ & $137(71.73)$ & \\
\hline Cardiac arrest & $12(9.16)$ & $18(9.42)$ & \\
\hline \multicolumn{4}{|l|}{ ECMO implantation site } \\
\hline ICU or ward & $59(45.04)$ & $80(41.88)$ & 0.647 \\
\hline Operation room & $72(54.96)$ & $111(58.12)$ & \\
\hline \multicolumn{4}{|l|}{ ECMO cannula } \\
\hline Femoral puncture & $34(25.95)$ & $43(22.51)$ & 0.718 \\
\hline Femoral incision & $87(66.41)$ & $135(70.68)$ & \\
\hline Transthoracic cannula & $10(7.64)$ & $13(6.81)$ & \\
\hline Duration of ECMO (hours) & $153.53 \pm 105.33$ & $105.21 \pm 71.79$ & $<0.001$ \\
\hline ECMO weaning success & $74(56.49)$ & $134(70.16)$ & 0.012 \\
\hline
\end{tabular}

$\mathrm{CPB}=$ cardiopulmonary bypass; $\mathrm{ECMO}=$ extracorporeal membrane oxygenation; $\mathrm{ICU}=$ intensive care unit

Table 3. Patients' major complications and in-hospital outcomes.

\begin{tabular}{|c|c|c|c|}
\hline Variables & $\begin{array}{l}\text { Infection group } \\
\qquad(n=131)\end{array}$ & $\begin{array}{l}\text { Non-infection group } \\
\qquad(\mathrm{n}=191)\end{array}$ & $P$-value \\
\hline \multicolumn{4}{|l|}{ Stroke } \\
\hline Ischemic & $2(1.52)$ & $4(2.09)$ & 0.798 \\
\hline Hemorrhagic & $5(3.82)$ & $5(2.62)$ & \\
\hline Major bleeding & $27(20.61)$ & $32(16.75)$ & 0.379 \\
\hline CRRT & $56(42.75)$ & $60(31.41)$ & 0.037 \\
\hline Limb ischemia requiring surgery & $4(3.05)$ & $5(2.62)$ & 0.996 \\
\hline \multicolumn{4}{|l|}{ Outcome of unweaning off ECMO } \\
\hline Death & $57(43.51)$ & $55(28.80)$ & 0.012 \\
\hline Cardiac transplantation & $0(0)$ & $2(1.04)$ & \\
\hline Survival to discharge & $55(41.98)$ & $103(53.92)$ & $<0.001$ \\
\hline
\end{tabular}

CRRT=continuous renal replacement therapy; ECMO=extracorporeal membrane oxygenation

BSI and RTI. Candida (70\%) was the main fungal pathogen. The pathogenic microorganisms of $\mathrm{NI}$ are showed in Table 4.

\section{Multivariate Analysis of Risk Factors for NI and In-Hospital Death}

Multivariate logistic regression analysis (Figure 3) revealed that body mass index (BMI) (adjusted odds ratio [OR]: 1.077; 95\% confidence interval $[\mathrm{Cl}]$ : 1.004-1.156; $P=0.039$ ) and duration of
ECMO support (OR: 1.006; 95\% Cl: 1.003-1.009; $P=0.0001)$ were independent risk factors for $\mathrm{ECMO}$-related $\mathrm{NI}$, and the risk of $\mathrm{NI}$ with 72-144 hours and $>144$ hours of ECMO support increased by 2.4 and 4.6 times than that of $<72$ hours of ECMO support, respectively. In terms of risk factors for BSI, Figure 4 showed that increased BMI (OR: 1.227; 95\% Cl: 1.019-1.477; $P=0.031$ ), transthoracic cannula (OR: 7.109; 95\% Cl: 1.022-49.446; $P=0.047$ ), and ECMO support $>72$ hours increased significantly the risk of BSI. For in-hospital death, Figure 5 revealed that age $>60$ years, 


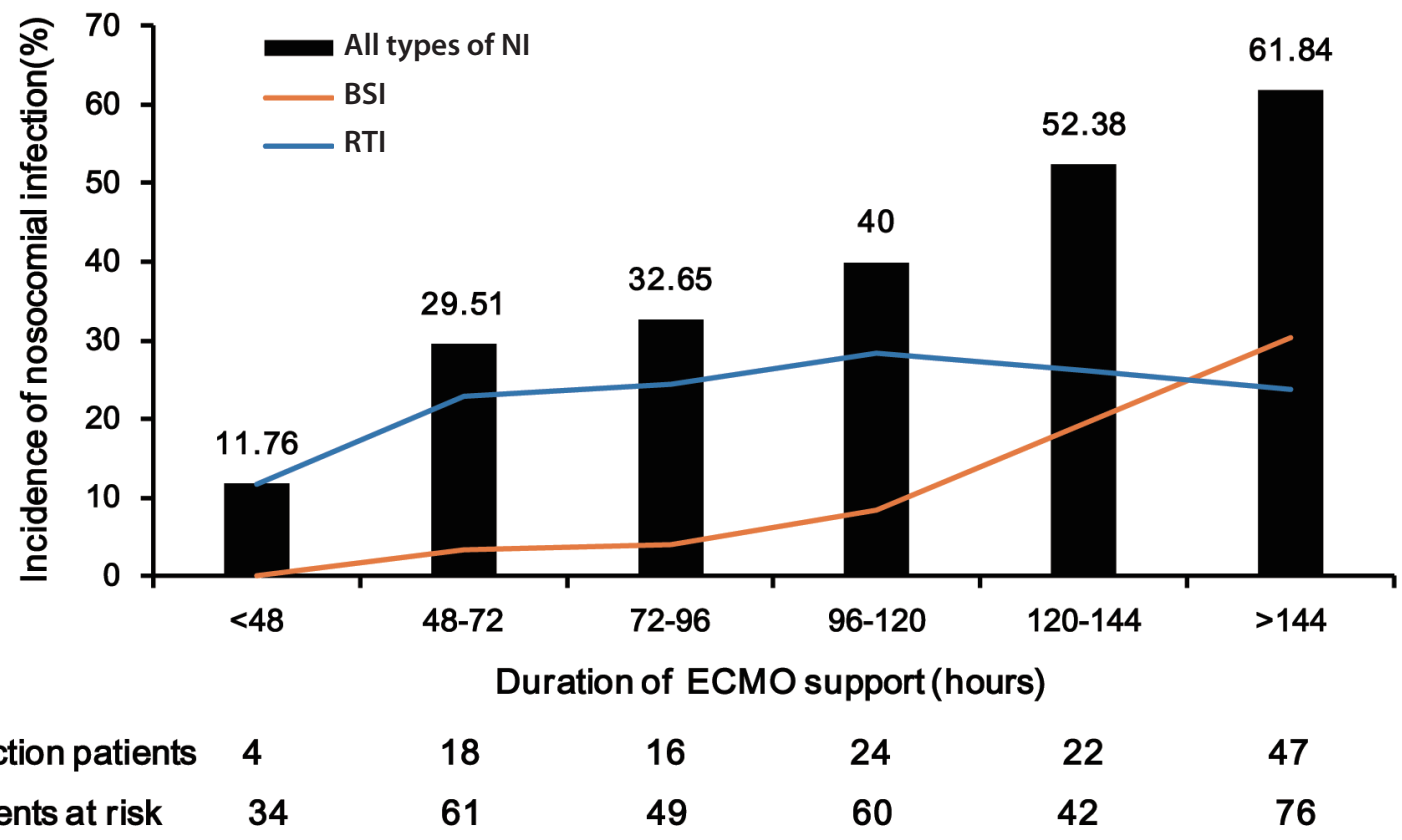

Fig. 1 - Incidence of nosocomial infection (NI) according to the duration of extracorporeal membrane oxygenation (ECMO) support. $B S I=$ blood stream infection; $R T I=$ respiratory tract infection

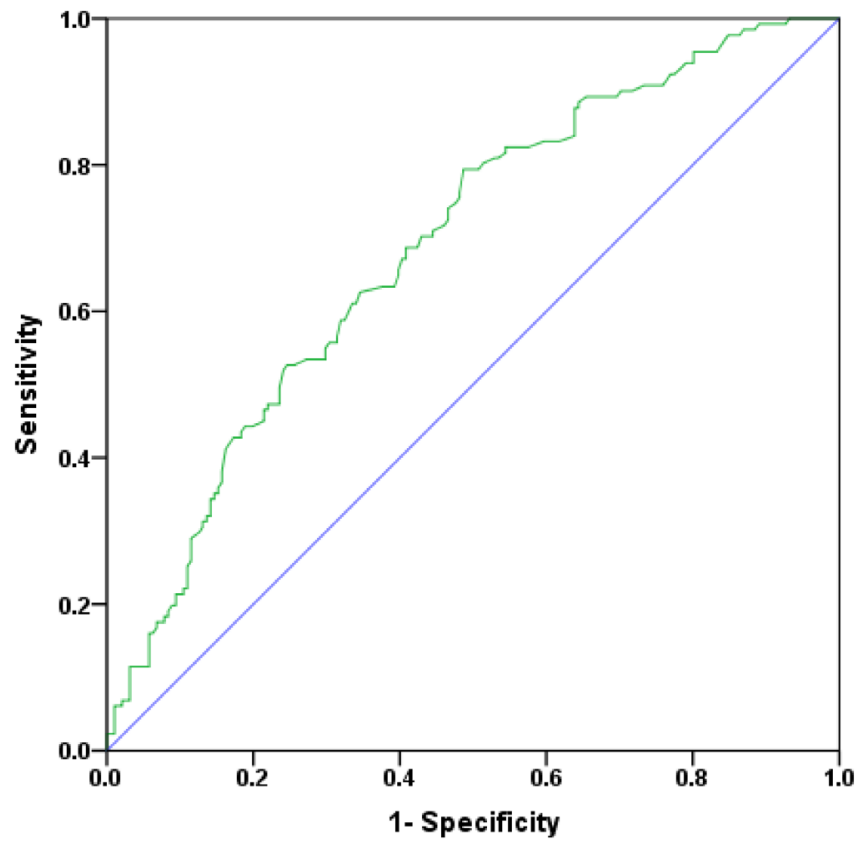

Fig. 2 - Receiver operation characteristic curve for predicting nosocomial infection with duration of extracorporeal membrane oxygenation support (area under the curve 0.689, 95\% confidence interval 0.631-0.747, $P<0.0001)$.
ECMO support > 144 hours, ECMO-related NI, and BSI increased significantly the risk of in-hospital death.

\section{DISCUSSION}

To the best of our knowledge, this investigation was the largest single-center observational study analyzing characteristics of ECMO-related $\mathrm{NI}$ in adult patients who underwent cardiac surgery. In this study, 40.68\% (131/322) of the patients suffered from $\mathrm{NI}$ during ECMO support with a $\mathrm{NI}$ incidence of 85.4 cases/1000 ECMO days. However, the latest literature reported that the rate of $\mathrm{NI}$ was $30.4 \%$ during ECMO support ${ }^{[7]}$, and the incidence of ECMO-related $\mathrm{NI}$ ranged from 11.92 to 43.3 cases/1000 ECMO days $^{[8,10]}$. The ECMO population was often companied by severe comorbidities, patients in our study were exposed to invasive procedures and suffered from severe surgical complications before ECMO support, which may increase the risk of ECMO-related NI. Moreover, the patients often required prolonging time of mechanical ventilation, central venous catheters, and urinary catheter, or there was an additional needing for intra-aortic balloon pump during ECMO support or continuous renal replacement therapy due to deleterious hemodynamic conditions after cardiac surgery, which also contributed to high incidence of ECMO-related NI in our study.

We evaluated causes of $\mathrm{NI}$ and found that prolonged duration of ECMO support was an independent risk factor for ECMO-related NI. Our result was in line with several previous studies $^{[11,12]}$. And our results also showed that BMI was an 
Table 4. Microorganism species causing ECMO-related NI.

\begin{tabular}{|c|c|c|c|c|c|}
\hline \multirow{2}{*}{ Microorganism species } & \multicolumn{4}{|c|}{ Samples [n (\%)] } & \multirow{2}{*}{$\begin{array}{l}\text { All patients } \\
\quad(n=131)\end{array}$} \\
\hline & Blood & $\begin{array}{l}\text { Tracheal } \\
\text { secretion }\end{array}$ & Wound secretion & Urine & \\
\hline Gram-negative pathogens & $119(51.07)$ & $106(45.49)$ & $6(2.58)$ & $2(0.86)$ & 233 \\
\hline Acinetobacter baumannii & $36(45.57)$ & $41(51.90)$ & $2(2.53)$ & $0(0)$ & 79 \\
\hline Pseudomonas aeruginosa & $15(46.88)$ & $17(53.12)$ & $0(0)$ & $0(0)$ & 32 \\
\hline Klebsiella pneumoniae & $18(60.00)$ & $11(36.67)$ & $1(3.33)$ & $0(0)$ & 30 \\
\hline Enterobacter cloacae & $16(84.21)$ & $0(0)$ & $1(5.26)$ & $2(10.53)$ & 19 \\
\hline Others & $34(46.58)$ & $37(50.68)$ & $2(2.74)$ & $0(0)$ & 73 \\
\hline Gram-positive pathogens & $45(44.55)$ & $50(49.50)$ & $5(4.95)$ & $1(0.99)$ & 101 \\
\hline Alpha streptococcus & $8(53.33)$ & $6(40.00)$ & $1(6.67)$ & $0(0)$ & 15 \\
\hline Micrococcus & $5(33.33)$ & $8(53.33)$ & $1(6.67)$ & $1(6.67)$ & 15 \\
\hline Micrococcus catarrhalis & $6(40.00)$ & $9(60.00)$ & $0(0)$ & $0(0)$ & 15 \\
\hline Staphylococcus epidermidis & $6(54.55)$ & $3(27.27)$ & $2(18.18)$ & $0(0)$ & 11 \\
\hline Others & $20(44.44)$ & $24(53.33)$ & $1(2.22)$ & $0(0)$ & 45 \\
\hline Fungi & $30(100)$ & $0(0)$ & $0(0)$ & $0(0)$ & 30 \\
\hline Candida albicans & $21(100)$ & $0(0)$ & $0(0)$ & $0(0)$ & 21 \\
\hline Candida tropicalis & $4(100)$ & $0(0)$ & $0(0)$ & $0(0)$ & 4 \\
\hline Others & $5(100)$ & $0(0)$ & $0(0)$ & $0(0)$ & 5 \\
\hline
\end{tabular}

ECMO-related $\mathrm{NI}=$ extracorporeal membrane oxygenation-related nosocomial infection

independent risk factor for ECMO-related NI. Some studies ${ }^{[13,14]}$ suggested that obesity was an independent risk factor for $\mathrm{NI}$. The precise mechanism of increasing risk of NI with increasing BMI remains unknown, but obesity is closely associated with impaired immune responses ${ }^{[15]}$, which may disturb the body's defense against infections.

Moreover, prolonged surgical time and CPB assist during surgery increased the risk of ECMO-related NI. Prolonged surgical time increased open chest duration, which increased the possibility of pathogens invasion. And CPB caused ischemiareperfusion injury of lung and induced systemic inflammatory response, which may disturb immune response, and then increase susceptibility to infections ${ }^{[16,17]}$. In addition, prolonged surgical time and CPB assist remarkably increased risk of multiple organ failure. And multiple organ failure was an independent risk factor for infections ${ }^{[18]}$. However, the multivariate regression analysis did show that prolonged surgical time and CPB assist were not independent risk factors for ECMO-related NI. Patients who have undergone prolonged surgical time and CPB assist were more susceptible to suffer from severe multiple organ failure, and then lost chance of ECMO support or death occurred within 48 hours of ECMO support, which might explain the abovementioned difference in our results.
Regarding the type of ECMO-related $\mathrm{NI}, \mathrm{BSI}$ was the most common in most studies, followed by RTI, UTI, and SWI ${ }^{[19,20]}$. But our study showed that RTI was predominant, followed by BSI, SWI, and UTI. Most patients were assisted by invasive mechanical ventilation before ECMO support and required prolonging mechanical ventilation due to severe heart failure, which may explain the difference of infection types between our ECMO cohort and the general ECMO cohort. Moreover, antibiotic prophylaxis may affect infection types. Despite of lacking studydemonstrated benefits, antibiotic prophylaxis is commonly used at ECMO centers, according to surveys of ELSO member sites ${ }^{[21,22]}$.

The pathogens species causing ECMO-related NI change with therapy chronology and antibiotics renewing. ELSO reported that the majority of culture-positive pathogens in patients who have undergone ECMO were coagulase-negative Staphylococci, Candida albicans, and Pseudomonas aeruginosa ${ }^{[23]}$. In our study, the Gram-negative bacilli were the most common pathogens, which were often isolated species in the ICU settings. And the most common pathogen causing BSI and RTI was Acinetobacter baumannii, which was conditioned pathogen. Severe morbidities after cardiac surgery might disturb the immune system and break ecological balance of the conditioned pathogen and the host, resulting in infections related to conditioned pathogen. In 


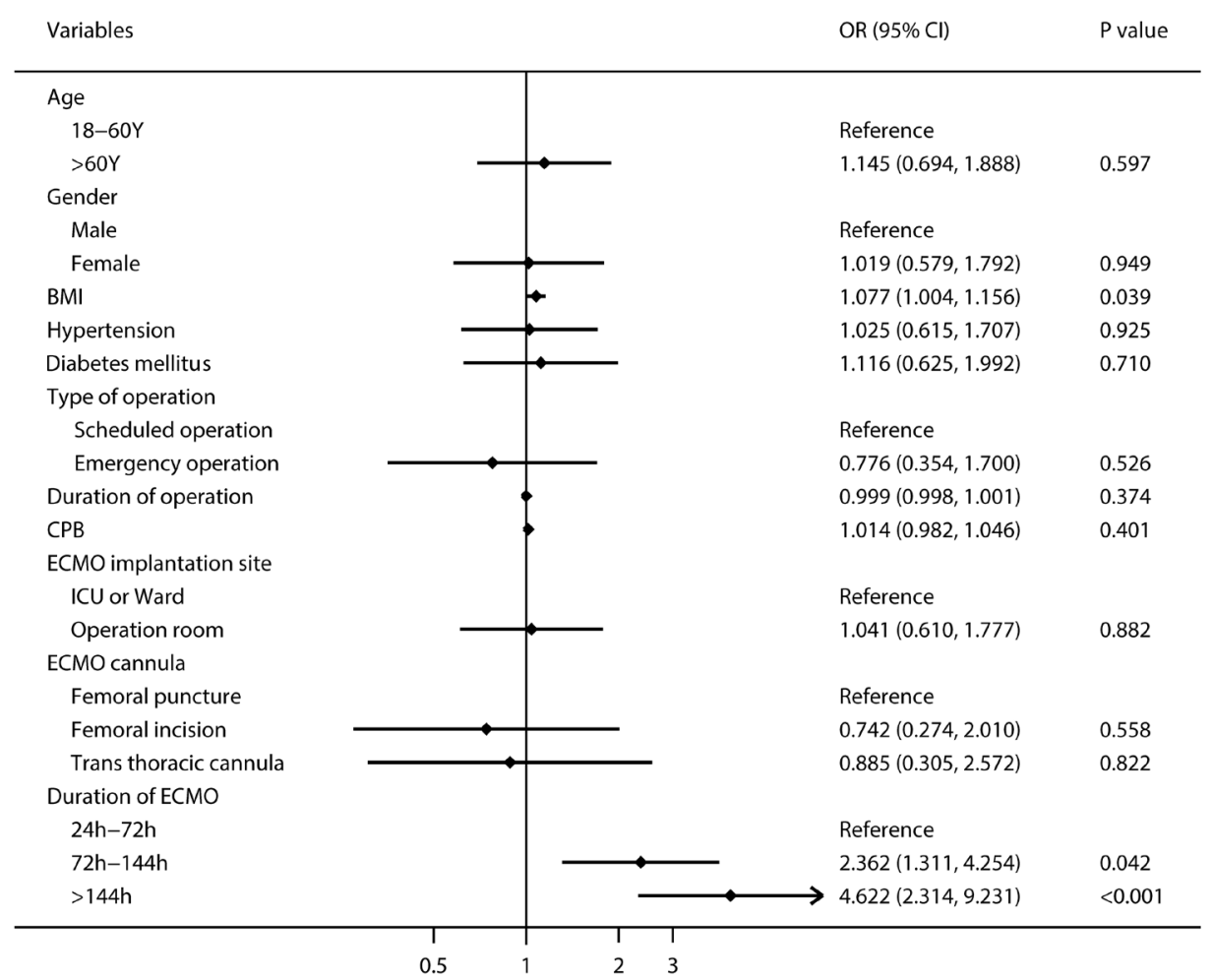

Fig. 3 - The multivariate logistic regression analysis of risk factors for extracorporeal membrane oxygenation (ECMO)-related nosocomial infection. $B M I=$ body mass index; $C l=$ confidence interval; $C P B=$ cardiopulmonary bypass; $/ C U=$ intensive care unit; $O R=0 d d$ ratio

\begin{tabular}{|c|c|c|c|}
\hline Variables & & OR $(95 \% \mathrm{Cl})$ & $P$ value \\
\hline \multicolumn{4}{|l|}{ Age } \\
\hline $18-60 Y$ & & Reference & \\
\hline$>60 \mathrm{Y}$ & & $3.174(0.940,10.718)$ & 0.063 \\
\hline \multicolumn{4}{|l|}{ Gender } \\
\hline Male & & Reference & \\
\hline Female & & $1.010(0.307,3.319)$ & 0.987 \\
\hline BMI & - & $1.227(1.019,1.477)$ & 0.031 \\
\hline Hypertension & & $0.510(0.147,1.771)$ & 0.289 \\
\hline Diabetes mellitus & - & $1.351(0.562,2.103)$ & 0.137 \\
\hline \multicolumn{4}{|l|}{ Type of operation } \\
\hline Scheduled operation & & Reference & \\
\hline Emergency operation & 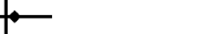 & $1.120(0.537,1.824)$ & 0.168 \\
\hline Duration of operation & & $0.999(0.996,1.002)$ & 0.735 \\
\hline CPB & & $1.857(0.917,8.701)$ & 0.216 \\
\hline \multicolumn{4}{|l|}{ ECMO implantation site } \\
\hline Operation room & & Reference & \\
\hline ICU or Ward & & $2.209(0.671,7.266)$ & 0.192 \\
\hline \multicolumn{4}{|l|}{ ECMO cannula } \\
\hline Femoral puncture & & Reference & \\
\hline Femoral incision & & $2.834(0.642,12.519)$ & 0.169 \\
\hline Trans thoracic cannula & & $7.109(1.022,49.446)$ & 0.047 \\
\hline \multicolumn{4}{|l|}{ Duration of ECMO } \\
\hline $24 \mathrm{~h}-72 \mathrm{~h}$ & & Reference & \\
\hline $72 h-144 h$ & & $4.422(2.069,8.900)$ & $<0.0001$ \\
\hline$>144 \mathrm{~h}$ & & $6.934(3.059,14.588)$ & $<0.0001$ \\
\hline
\end{tabular}

Fig. 4 - The multivariate logistic regression analysis of risk factors for extracorporeal membrane oxygenation (ECMO)-related blood stream infection. $B M I=$ body mass index; $C l=$ confidence interval; $C P B=$ cardiopulmonary bypass; $I C U=$ intensive care unit; $O R=0 d d$ s ratio 
$\begin{array}{lll}\text { Variables } & \mathrm{OR}(95 \% \mathrm{Cl}) \quad \mathrm{P} \text { value }\end{array}$

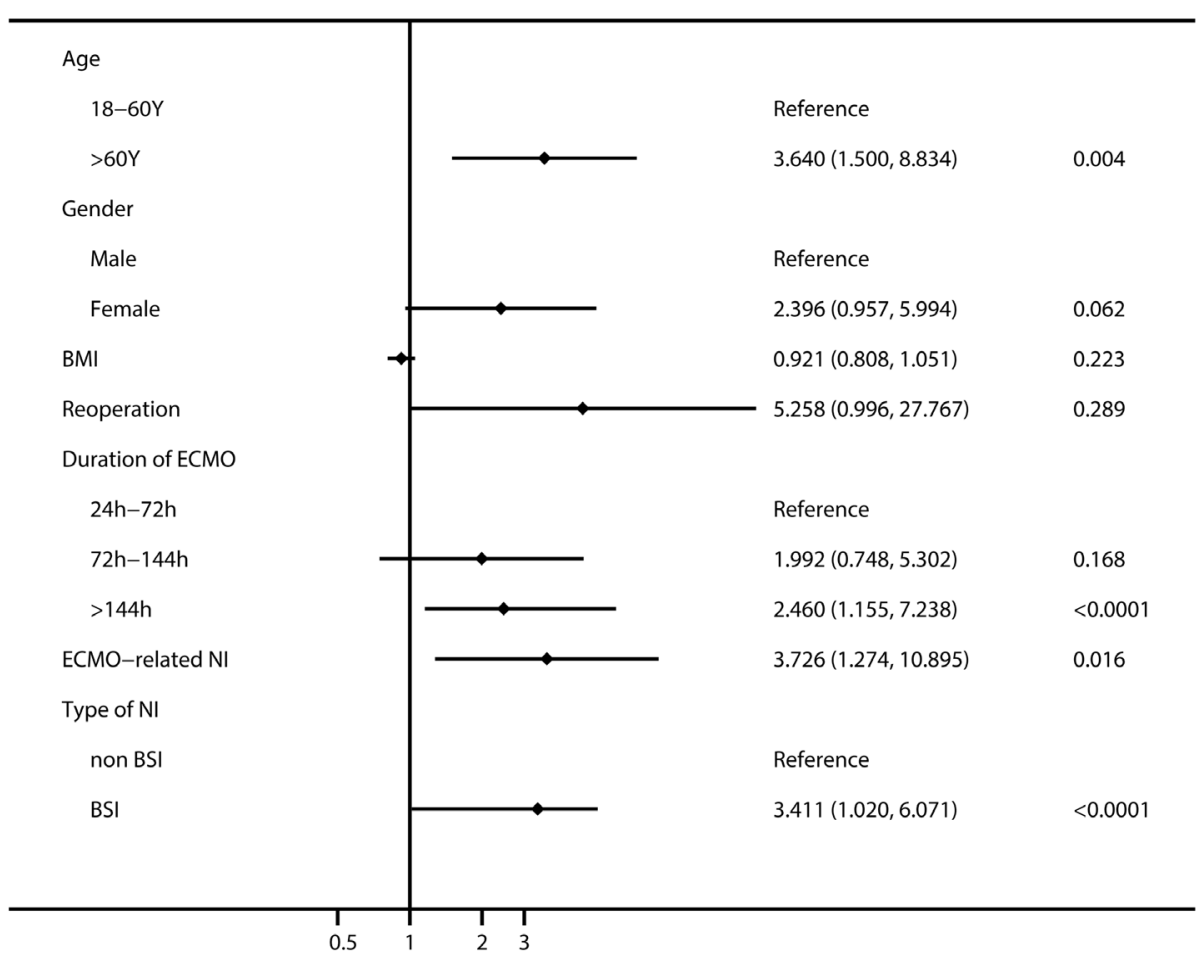

Fig. 5 - The multivariate logistic regression analysis of risk factors for in-hospital death. BMI=body mass index; $B S I=b l o o d$ stream infection; $\mathrm{Cl}=$ confidence interval; $\mathrm{ECMO}=$ extracorporeal membrane oxygenation; $\mathrm{NI}=$ nosocomial infection; $\mathrm{OR}=$ odds ratio

addition, Candida was the main fungal pathogen in both BSI and RTI, which was associated with prolonged use of wide-spectrum antibiotics during ECMO support.

\section{Limitations}

This study had limitations regarding susceptibility to inherent bias from retrospective data from a single center. But a homogeneous cohort and relatively large number of patients allowed us to draw strong conclusions.

\section{CONCLUSION}

The prolonged duration of ECMO support was an independent risk factor for $\mathrm{NI}$ after cardiac surgery. Therefore, the best strategies to prevent ECMO-related $\mathrm{NI}$ in these patients were as follows: timely surgery correcting causes of cardiopulmonary failure - such as myocardial ischemia due to susceptible acute occlusion of grafts, unsatisfactory repair of heart valves, and delayed cardiac tamponade to shortening duration of ECMO support - and considering to wean mechanical ventilation whenever possible, when patients meet protocols of extubation.

\section{ACKNOWLEDGEMENTS}

We thank all the participating colleagues and nurses for their assistance in the building of case data.
Financial support: This study was funded by the National Key Research and Development Program of China 2016YFC1301001.

\section{No conflict of interest.}

\section{Authors' roles \& responsibilities}

JW Substantial contributions to the conception or design of the work; or the acquisition, analysis, or interpretation of data for the work; drafting the work or revising it critically for important intellectual content; final approval of the version to be published

LW Acquisition, analysis, or interpretation of data for the work; final approval of the version to be published

MJ Acquisition, analysis, or interpretation of data for the work; final approval of the version to be published

ZD Acquisition of data for the work; final approval of the version to be published

$\mathrm{XH} \quad$ Interpretation of data for the work; drafting the work or revising it critically for important intellectual content; final approval of the version to be published 


\section{REFERENCES}

1. Grasselli G, Scaravilli V, Di Bella S, Biffi S, Bombino M, Patroniti N, et al. Nosocomial infections during extracorporeal membrane oxygenation: incidence, etiology, and impact on patients' outcome. Crit Care Med. 2017:45(10):1726-33. doi:10.1097/CCM.0000000000002652.

2. Kim DW, Yeo HJ, Yoon SH, Lee SE, Lee SJ, Cho WH, et al. Impact of bloodstream infections on catheter colonization during extracorporeal membrane oxygenation. J Artif Organs. 2016;19(2):128-33. doi:10.1007/ s10047-015-0882-5.

3. Kuehn C, Orszag P, Burgwitz K, Marsch G, Stumpp N, Stiesch M, et al. Microbial adhesion on membrane oxygenators in patients requiring extracorporeal life support detected by a universal rDNA PCR test. ASAIO J. 2013;59(4):368-73.

4. Ayyıldız P, KasarT, Ozturk E, Yildiz O, Ozturk S, ErgulY, et al. The evaluation of nosocomial infections in pediatric patients with extracorporeal membrane oxygenation support. Braz J Cardiovasc Surg. 2017;32(6):46874. doi:10.21470/1678-9741-2017-0072.

5. Haneke F, Schildhauer TA, Schlebes AD, Strauch JT, Swol J. Infections and extracorporeal membrane oxygenation: incidence, therapy, and outcome. ASAIO J. 2016;62(1):80-6.

6. Bizzarro MJ, Conrad SA, Kaufman DA, Rycus P; Extracorporeal Life Support Organization Task Force on Infections, Extracorporeal Membrane Oxygenation. Infections acquired during extracorporeal membrane oxygenation in neonates, children, and adults. Pediatr Crit Care Med. 2011;12(3):277-81. doi:10.1097/PCC.0b013e3181e28894.

7. Ali J, Vuylsteke A. Extracorporeal membrane oxygenation: indications, technique and contemporary outcomes. Heart. 2019;105(18):1437-43. doi:10.1136/heartjnl-2017-311928.

8. Hsu MS, Chiu KM, Huang YT, Kao KL, Chu SH, Liao CH. Risk factors for nosocomial infection during extracorporeal membrane oxygenation. J Hosp Infect. 2009;73(3):210-6. doi:10.1016/j.jhin.2009.07.016.

9. Garner JS, Jarvis WR, Emori TG, Horan TC, Hughes JM. CDC definitions for nosocomial infections, 1988. Am J Infect Control. 1988;16(3):12840. Erratum in: Am J Infect Control 1988;16(4):177. doi:10.1016/01966553(88)90053-3.

10. Kim GS, Lee KS, Park CK, Kang SK, Kim DW, Oh SG, et al. Nosocomial infection in adult patients undergoing veno-arterial extracorporeal membrane oxygenation. J Korean Med Sci. 2017;32(4):593-8. doi:10.3346/jkms.2017.32.4.593.

11. Sun HY, Ko WJ, Tsai PR, Sun CC, Chang YY, Lee CW, et al. Infections occurring during extracorporeal membrane oxygenation use in adult patients. JThorac Cardiovasc Surg. 2010;140(5):1125-32.e2. doi:10.1016/j. jtcvs.2010.07.017.
12. Aubron C, Cheng AC, Pilcher D, Leong T, Magrin G, Cooper DJ, et al. Infections acquired by adults who receive extracorporeal membrane oxygenation: risk factors and outcome. Infect Control Hosp Epidemiol. 2013;34(1):24-30. doi:10.1086/668439.

13. Huttunen R, Karppelin M, Syrjänen J. Obesity and nosocomial infections. J Hosp Infect. 2013;85(1):8-16. doi:10.1016/j.jhin.2013.06.012.

14. Falagas ME, Kompoti M. Obesity and infection. Lancet Infect Dis. 2006;6(7):438-46. doi:10.1016/\$1473-3099(06)70523-0.

15. Dobner J, Kaser S. Body mass index and the risk of infection - from underweight to obesity. Clin Microbiol Infect. 2018;24(1):24-8. doi:10.1016/j.cmi.2017.02.013.

16. Millar JE, Fanning JP, McDonald Cl, McAuley DF, Fraser JF. The inflammatory response to extracorporeal membrane oxygenation (ECMO): a review of the pathophysiology. Crit Care. 2016;20(1):387. doi:10.1186/s13054-016-1570-4.

17. Al-Fares A, Pettenuzzo T, Del Sorbo L. Extracorporeal life support and systemic inflammation. Intensive Care Med Exp. 2019;7(Suppl 1):46. doi:10.1186/s40635-019-0249-y.

18. Vincent JL, Moreno R, Takala J, Willatts S, De Mendonça A, Bruining H, et al. The SOFA (sepsis-related organ failure assessment) score to describe organ dysfunction/failure. On behalf of the working group on sepsisrelated problems of the European society of intensive care medicine. Intensive Care Med. 1996;22(7):707-10. doi:10.1007/BF01709751.

19. Biffi S, Di Bella S, Scaravilli V, Peri AM, Grasselli G, Alagna L, et al. Infections during extracorporeal membrane oxygenation: epidemiology, risk factors, pathogenesis and prevention. Int J Antimicrob Agents. 2017;50(1):9-16. doi:10.1016/j.ijantimicag.2017.02.025.

20. Brown KL, Ridout DA, Shaw M, Dodkins I, Smith LC, O'Callaghan MA, et al. Healthcare-associated infection in pediatric patients on extracorporeal life support: the role of multidisciplinary surveillance. Pediatr Crit Care Med. 2006;7(6):546-50. doi:10.1097/01.PCC.0000243748.74264.CE.

21. Müller T, Lubnow M, Philipp A, Schneider-Brachert W, Camboni D, Schmid C, et al. Risk of circuit infection in septic patients on extracorporeal membrane oxygenation: a preliminary study. Artif Organs. 2011;35(4):E84-90. doi:10.1111/j.1525-1594.2010.01185.x.

22. Kao LS, Fleming GM, Escamilla RJ, Lew DF, Lally KP. Antimicrobial prophylaxis and infection surveillance in extracorporeal membrane oxygenation patients: a multi-institutional survey of practice patterns. ASAIO J. 2011;57(3):231-8. doi:10.1097/MAT.0b013e31820d19ab.

23. Abrams D, Grasselli G, Schmidt M, MuellerT, Brodie D. ECLS-associated infections in adults: what we know and what we don't yet know. Intensive Care Med. 2020;46(2):182-91. doi:10.1007/s00134-019-05847-z. 